\title{
Assessment Methods and How Teachers and Students View Them in a Computer Science Course at Uppsala University
}

\author{
Mithat Canberk Ezel \\ Computer and Instructional Technology Teaching Education \\ Bilkent University, Ankara \\ m_ezel@ug.bilkent.edu.tr
}

\begin{abstract}
I have examined concepts of assessments and aimed to see differences between teachers and students opinions. I created a questionnaire and sent it to three groups in CS department at Uppsala University. These groups were undergraduate student, graduate students and teachers in CS.
\end{abstract}

\section{Categories \& Subject Descriptors}

I. Computing Methodologies; I.m MISCELLANEOUS

\section{General Terms}

Documentation

\section{Keywords}

methodology, research, examination, grade

\section{INTRODUCTION AND MOTIVATION}

Assessment is an elementary part in the learning process by which teachers assure that the student have actually learned, it is also the part that encourage the student to learn. I have tried to capture some general methods of assessments, using my own experience from courses I have taken, and see how both teachers and students view them. By doing this I hoped to learn how to improve some of these methods.

\section{Methodology}

I conducted our research using a quantitative research approach, as I want to validate the ideas that we have about assessments. I created an on-line questionnaire to collect my data which contained 22 statements in total, 11 statements and an additional 11 contradictory statements. Each statement pair described a certain idea or base question that we wanted my participants to answer. The questionnaire was distributed to several groups in the CS department at Uppsala University. 43 participants took

my survey; four teachers, twenty three graduate students, and sixteen undergraduate students. The answers from the questionnaire were arranged according to the 3 groups in the survey, the data was analyzed, and the results of each idea (base question) was calculated for each group.

\section{RESULTS AND CONCLUSION}

Below I am going to present some of the most interesting results and what I concluded from them.

-Teachers prefers that students study course literature to understand better, students prefer lecture slides and think that the slides should be enough for them to pass the course. I explain the different views of this as the teachers understand that the book can explain much better as it contains more details about the materials in the course. But students preferred slides as they may not be able to afford the book or may be they think that reading books are too time-consuming.

-Teachers are against optional written exams, but the students prefer it. Teacher are against this because they won't be able to determine if the student has actually learned enough or not. Students thinks it is acceptable as the examination will only be for students that want to get higher grade (more than 3 ).

-Group working on assignments is supported by all the three groups. My conclusion is that working in groups is preferred both by students and teachers and it certainly helps the process of learning.

- Students and teachers agree that the teacher of the course is important. By this I conclude that most of the students check the teacher who is giving the course before taking the course.

\section{DISCUSSION}

Assessment is a very active part in the learning process, there where many ideas that I got and more questions regarding the methods that is used and whether they are acceptable for both students and teacher or not. Time boundaries of the project and my efforts to make the survey as short as possible made me satisfied with the questions that I had formulated. I believe that the results is quite acceptable and it showed me the different views that the methods can be seen with. This project was also a process of learning for myself as computer science student and as teachers. I have certainly identified my weak points and also my strong ones and I am sure that I will conduct much better studies in the future.

I hope that I have presented at least a few good ideas about what types of assessment is better than others and how some of them could be improved. 